\title{
Chinese Poplar Propolis Inhibits MDA-MB-231 Cell Proliferation in an Inflammatory Microenvironment by Targeting Enzymes of the Glycolytic Pathway
}

\author{
Junya Li, ${ }^{1}$ Hui Liu, ${ }^{1}$ Xinying Liu, ${ }^{2}$ Shengyu Hao $\mathbb{D}^{D},{ }^{3}$ Zihan Zhang, ${ }^{1}$ and Hongzhuan Xuan $\mathbb{D}^{1}$ \\ ${ }^{1}$ School of Life Science, Liaocheng University, Liaocheng 252059, China \\ ${ }^{2}$ Center of Bee Industry on Seed-Breeding and Popularization in Shandong Province, Jinan 250010, China \\ ${ }^{3}$ School of Physical Science and Information Technology, Liaocheng University, Liaocheng 252059, China
}

Correspondence should be addressed to Hongzhuan Xuan; hongzhuanxuan@163.com

Received 16 December 2020; Revised 24 January 2021; Accepted 2 February 2021; Published 15 February 2021

Academic Editor: Kai Wang

Copyright ( $\odot 2021$ Junya Li et al. This is an open access article distributed under the Creative Commons Attribution License, which permits unrestricted use, distribution, and reproduction in any medium, provided the original work is properly cited.

\begin{abstract}
Propolis is rich in flavonoids and has excellent antitumor activity. However, little is known about the potential effects of propolis on glycolysis in tumor cells. Here, the antitumor effects of propolis against human breast cancer MDA-MB-231 cells in an inflammatory microenvironment stimulated with lipopolysaccharide (LPS) were investigated by assessing the key enzymes of glycolysis. Propolis treatment obviously inhibited MDA-MB-231 cell proliferation, migration and invasion, clone forming, and angiogenesis. Proinflammatory mediators, including tumor necrosis factor-alpha (TNF- $\alpha$ ), interleukin (IL)- $1 \beta$, and IL- 6 , as well as NLRP3 inflammasomes, were decreased following propolis treatment when compared with the LPS group. Moreover, propolis treatment significantly downregulated the levels of key enzymes of glycolysis-hexokinase 2 (HK2), phosphofructokinase (PFK), pyruvate kinase muscle isozyme M2 (PKM2), and lactate dehydrogenase A (LDHA) in MDA-MB231 cells stimulated with LPS. After treatment with 2-deoxy-D-glucose (2-DG), an inhibitor of glycolysis, the inhibitory effect of propolis on migration was not significant when compared with the LPS group. In addition, propolis increased reactive oxygen species (ROS) levels and decreased mitochondrial membrane potential. Taken together, these results indicated that propolis targeted key enzymes of glycolysis to suppress the proliferation of MDA-MB-231 cells in an inflammatory microenvironment. These studies provide a molecular basis for propolis as a natural anticancer agent against breast cancer.
\end{abstract}

\section{Introduction}

Breast cancer $(\mathrm{BC})$ is one of the most common malignant tumors and a major cause of cancer death among women worldwide, and the triple-negative breast cancer (TNBC) subtype is the most aggressive one [1]. Worldwide statistics showed that in 2018, approximately two million new cases were detected, with the total $\mathrm{BC}$ cases accounting for $11.6 \%$ of all cancers. Therefore, the search for effective anticancer agents is urgent for $\mathrm{BC}$ therapy and to improve the quality of life of patients.

In recent years, the antitumor activities of flavonoids have attracted increasing interest among researchers. Propo- lis, rich in flavonoids, is a resinous substance collected by honeybees (Apis mellifera) from various plant sources. It has been used as a folk medicine since ancient times [2].

According to its different plant sources, propolis can be divided into five categories: Populus propolis, Baccharis propolis, Clusia propolis, Macaranga propolis, and Mediterranean propolis [3]. More than 200 flavonoids have been identified from various kinds of propolis around the world [4]. Chinese propolis (CP), one of the Populus type of propolis, mainly contains flavonoids and phenolic compounds and has exhibited extensive pharmacological activities including antibacterial [5], anti-inflammatory [6], antivirus [7], antitumor [8], antioxidant [9], and immunoregulation activities [10]. 
We and other researchers demonstrated that propolis has an excellent antitumor activity against various tumor cell lines in vivo and in vitro $[8,11]$. Furthermore, we reported that Chinese propolis and its major constituent-caffeic acid phenethyl ester (CAPE) - inhibit breast cancer cell proliferation in an inflammatory microenvironment by inhibiting the Toll-like receptor 4 (TLR4) signal pathway and inducing apoptosis and autophagy [12]. However, these antitumor mechanisms have still not been fully elucidated.

The mitochondria are the center of energy and metabolism in eukaryons. Warburg revealed the unique energy metabolism in cancer cells, suggesting a shift in energy production from mitochondrial oxidative phosphorylation (OXPHOS) to aerobic glycolysis [13]. Alterations in the glucose metabolism are characterized by increased uptake of glucose, hyperactivated glycolysis, decreased OXPHOS component, and the accumulation of lactate. Cancer cells rely on higher rates of aerobic glycolysis as their primary source of energy; thus, aerobic glycolysis becomes a hallmark of cancer cells. Key enzymes of glycolysis, namely, hexokinase 2 (HK2), phosphofructokinase (PFK), pyruvate kinase muscle isozyme M2 (PKM2), and lactate dehydrogenase A (LDHA), are critical glycolysis regulators [14]. Enhanced glycolysis correlates with the upregulation and activation of critical glycolytic enzymes, which, in turn, promotes proliferation, metastasis, and tumorigenesis [15]. Inhibition of glycolysis has been identified as a novel therapeutic focus in cancer therapies.

The levels of HK2, PFK, PKM2, and LDHA have been individually reported to be correlated with cancer cell growth [16-19]. Propolis has excellent antitumor activities, and whether propolis could target crucial glycolytic enzymes to inhibit tumor cell proliferation is still unclear. In the present study, the roles of Chinese propolis on key glycolytic enzymes-HK2, PFK, PKM2, and LDHA-were assessed in MDA-MB-231 cells stimulated with lipopolysaccharide (LPS).

\section{Materials and Methods}

2.1. Chemicals and Reagents. Leibovitz's L15 medium and fetal bovine serum (FBS) were purchased from Gibco-BRL (USA). LPS from Escherichia coli 055 : B5,2' $7^{\prime}$-dichlorodihydrofluorescein diacetate (DCFH-DA) and JC-1 was obtained from Sigma-Aldrich (St. Louis, USA). Matrigel basement membrane matrix was obtained from BD Biocoat (USA). The Enhanced Cell Counting Kit- 8 was obtained from Beyotime (China). Primary antibodies against $\beta$-actin, GAPDH, HK2, PFK, PKM2, LDHA, NLRP3, and secondary antibody were obtained from ABclonal Biotech (USA). Enzyme-linked immunosorbent assay (ELISA) kits for HK2, PFK, PKM2, and LDHA were obtained Shanghai Enzyme-linked Biotechnology Co., Ltd. (China). A secondary antibody for immunofluorescence and donkey antirabbit IgG Alexa Fluor-488 was purchased from Life Technologies (USA).

2.2. Preparation of Chinese Propolis Extract. Chinese propolis was collected from Nanyang in Henan province, located in North China in 2017 (voucher specimen no. CP17110702), and the main plant origin of the propolis sample collected was poplar (Populus sp.). The propolis was firstly frozen and then extracted with 95\% (v/v) ethanol. The extracted propolis was then ultrasonicated at $40^{\circ} \mathrm{C}$ for $3 \mathrm{~h}$. The supernatant of the extracted propolis was filtered with filter papers to remove the residues, and then the propolis was extracted again three times. Thereafter, all of the supernatants were combined and evaporated with a rotary evaporator under reduced pressure at $50^{\circ} \mathrm{C}$. Then, the concentrate was further evaporated in an oven at $50^{\circ} \mathrm{C}$ until reaching a constant weight and was stored at $-20^{\circ} \mathrm{C}$. The ethanol extracted Chinese propolis (EECP) was redissolved in ethanol before use. The major chemical constituents of the EECP were analyzed via HPLC-DAD/Q-TOF-MS as previously described [20].

2.3. Cell Culture. The human breast cancer cell line MDAMB-231 was purchased from Cell Bank of Typical Culture Preservation Committee, Chinese Academy of Sciences, Shanghai (Shanghai, China). Cells were cultured in Leibovitz's L15 medium supplemented with $10 \%$ (v/v) FBS, $100 \mathrm{U} / \mathrm{mL}$ of penicillin, and $100 \mu \mathrm{g} / \mathrm{mL}$ streptomycin at $37^{\circ} \mathrm{C}$.

2.4. Exposure of $M D A-M B-231$ to EECP. When the MDAMB-231 cells reached $80 \%-90 \%$ confluence, they were divided into 3 groups for treatment: (a) culture in L15 medium (control group), (b) culture in L15 medium with $1 \mu \mathrm{g} / \mathrm{mL}$ LPS (LPS group), and (c) culture in L15 medium with $1 \mu \mathrm{g} / \mathrm{mL}$ LPS and EECP $(25,50$, and $100 \mu \mathrm{g} / \mathrm{mL})$ (test group). EECP was dissolved in ethanol and applied to the cells, with a final ethanol concentration in the culture medium of $<0.1 \%(\mathrm{v} / \mathrm{v})$. Ethanol at a concentration of $0.1 \%$ (v/v) did not affect the cell viability.

2.5. Cell Viability Assay. Cell viability was measured using the CCK- 8 kit. Cells $\left(1 \times 10^{5}\right.$ cells/well $)$ were seeded in 96 -well plates. When cells reached $60-70 \%$ confluence, they were treated with or without $\operatorname{EECP}(25,50$, and $100 \mu \mathrm{g} / \mathrm{mL})$ and LPS $(1 \mu \mathrm{g} / \mathrm{mL})$. At 12,24 , and $48 \mathrm{~h}$, cell viabilities were measured following the manufacturer's instructions. The optical density was determined at $450 \mathrm{~nm}$.

2.6. Transwell Analysis. MDA-MB-231 cells were seeded into 6-wells plates. The medium was replaced with fresh complete medium or medium containing $1 \mu \mathrm{g} / \mathrm{mL}$ LPS alone or LPS with $\operatorname{EECP}(25,50$, and $100 \mu \mathrm{g} / \mathrm{mL})$ when cells reached $70 \%$ confluence. The cells were further incubated for $24 \mathrm{~h}$. Thereafter, the cells were treated with trypsin, resuspended in serumfree medium, and seeded into the upper chamber of the Transwell. Serum-free medium containing $5 \times 10^{4}$ cells was added to the upper chamber for migration assays, whereas $1 \times 10^{5}$ cells were used for Matrigel invasion assays. L15 medium with $20 \%$ FBS was added to the lower chamber. After incubation for $24 \mathrm{~h}$, the cells were fixed with $95 \%(\mathrm{v} / \mathrm{v})$ ethanol for $10 \mathrm{~min}$, then stained with $0.1 \%$ crystal violet solution for $30 \mathrm{~min}$ and pictured under a microscope. The migration and invasion rates of cells were counted using Image J software.

2.7. Endothelial Cell Tube Formation Assay. Matrigel was diluted with serum-free medium, and $200 \mu \mathrm{L}$ of diluent was added into a 24 -well plate and maintained at $37^{\circ} \mathrm{C}$ for 1 hour. 
Then, $1 \times 10^{5}$ human umbilical vein endothelial cells (HUVECs) were treated with trypsin, resuspended in serum-free medium, and gently seeded on Matrigel-coated wells. Two hours later, cells were treated with EECP (25, 50 , or $100 \mu \mathrm{g} / \mathrm{mL})$ and LPS $(1 \mu \mathrm{g} / \mathrm{mL})$. Endothelial cell tube formation was photographed through an inverted microscope at $6 \mathrm{~h}$. The total tube numbers and branches were calculated using ImageJ software.

2.8. Colony Formation Assay. MDA-MB-231 cells were seeded into a 6-well plate at $1 \times 10^{3}$ cells/well and cultured for $24 \mathrm{~h}$. Then, cells were treated with $\operatorname{EECP}(25,50$, and $100 \mu \mathrm{g} / \mathrm{mL})$ and LPS $(1 \mu \mathrm{g} / \mathrm{mL})$ for $24 \mathrm{~h}$. After that, the medium was replaced with fresh complete medium. The medium was changed every three days. Ten days later, cell colonies were washed with phosphate-buffered saline and fixed with $95 \%(\mathrm{v} / \mathrm{v})$ ethanol. Then, cells were stained with $0.1 \%$ crystal violet and captured under an inverted optical microscope. ImageJ software was used to count the numbers of cells.

2.9. Western Blot Assay. After treatment with $\operatorname{EECP}(25,50$, and $100 \mu \mathrm{g} / \mathrm{mL}$ ) for $24 \mathrm{~h}$, the total protein was extracted using a commercial protein extraction kit. The protein concentration was measured using a BCA protein assay kit. Subsequently, equal amounts of protein $(30 \mu \mathrm{g})$ were separated via $12 \%$ SDS-PAGE. The gels were then transferred to polyvinylidene fluoride (PVDF) membranes. Skim milk (5\%) was used to block the nonspecific binding sites for $1 \mathrm{~h}$ at room temperature. Primary antibodies (HK2, PFK, PKM2, LDHA, and NLRP3) were incubated with the membranes at $4^{\circ} \mathrm{C}$ overnight, and horseradish peroxidase- (HRP-) conjugated secondary antibodies were then applied for another $1 \mathrm{~h}$ of incubation at room temperature. The immunoreactive signals were detected under an Amersham Image 600 (USA), and the relative quantity of protein was analyzed using ImageJ software.

2.10. Reverse Transcription-Quantitative Polymerase Chain Reaction (RT-PCR) Assay. After treatment with EECP (25, 50 , and $100 \mu \mathrm{g} / \mathrm{mL}$ ) for $24 \mathrm{~h}$, the total RNA of cells was extracted using an RNA extraction kit (Carry Helix, China) according to the manufacturer's protocol. Then, the cDNA was reversed from RNA using a PrimeScript RT Kit (Thermo \#K1622). The primers used in the present study are listed in Table 1. Quantitative real-time PCR was performed using the SYBR Green PCR reagent Kit (Thermo F-415XL). The expression of the housekeeping gene GAPDH was used to normalize the expression levels, and the results were expressed as $2^{-\Delta \Delta \mathrm{Ct}}$.

2.11. ELISA Assay. The levels of glycolytic key enzymes-HK2, PFK, PKM2, and LDHA and proinflammatory cytokinesTNF- $\alpha$, IL- $1 \beta$, and IL- 6 in cell supernatant after EECP (25, 50 , and $100 \mu \mathrm{g} / \mathrm{mL}$ ) treatment were measured using commercial ELISA kits following standard protocols.

2.12. Immunofluorescence Assay. After treatment with EECP $(25,50$, and $100 \mu \mathrm{g} / \mathrm{mL})$ for $24 \mathrm{~h}$, cells were fixed with $4 \%$ paraformaldehyde $(\mathrm{w} / \mathrm{v})$ at room temperature for $15 \mathrm{~min}$,
TABle 1: Primer sequences for genes.

\begin{tabular}{|c|c|}
\hline Gene $(\mathrm{R})$ & Sequence \\
\hline \multirow{2}{*}{ LDHA } & F: $5^{\prime}$-TTCAGCCCGATTCCGTTAC-3' \\
\hline & R: 5'-AGACACCAGCAACATTCATTCC-3' \\
\hline \multirow{2}{*}{ HK2 } & F: $5^{\prime}$-GCTTGCCTACTTCTTCACG-3' \\
\hline & R:5' -TTTCTCCATCTCCTTGCG-3' \\
\hline \multirow{2}{*}{ PFK } & F:5'-ACAGAAGCCTTGGTCTAACAC-3' \\
\hline & R:5'-GGAGAGTTGGAGGAATCAGTAG-3 \\
\hline \multirow{2}{*}{ PKM2 } & F:5'-CCAGGTGAAGCAGAAAGGT-3' \\
\hline & R:5'-CGGATGAATGACGCAAACA-3' \\
\hline \multirow{2}{*}{ GAPDH } & F:5'-AGAAGGCTGGGGCTCATTTG-3' \\
\hline & R:5'-AGGGGCCATCCACAGTCTTC-3' \\
\hline \multirow{2}{*}{ IL- $1 \beta$} & F: $5^{\prime}$-GCTCGCCAGTGAAATGATG-3' \\
\hline & R: 5'-TGGTGGTCGGAGATTCGTAG-3' \\
\hline
\end{tabular}

then blocked with $5 \%$ donkey serum (v/v) for 20 min. After adding the primary antibodies for PKM2 and LDHA $(1: 100)$ and secondary antibody $(1: 200)$ (FITC-IgG), a laser scanning confocal microscope (Olympus FV1200, Japan) was used for fluorescence detection. For analysis, ImageJ was used as software. Images are representative of three independent experiments.

2.13. Reactive Oxygen Species (ROS) and Mitochondrial Membrane Potential Assay. The fluorescent probes, DCFHDA and JC-1, were used to test ROS production and mitochondrial membrane potential, respectively, according to the manufacturer's protocol. The levels of ROS and mitochondrial membrane potential were quantified using the software accompanying laser scanning confocal microscope (Olympus FV1200, Japan). ROS results were shown as the relative fluorescence intensity ratio compared with the LPS group, and mitochondrial membrane potential results were shown as the ratio of red to green fluorescence as compared with the LPS group.

2.14. Statistical Analysis. All experiments were repeated at least three times independently. Data were expressed as the mean \pm SEM. Statistical analysis involved paired Student's $t$ -test and ANOVA via SPSS version 18.0 and Graphpad Prism 5. A $P$ value of $<0.05$ was considered to indicate a statistically significant difference.

\section{Results}

3.1. The Major Chemical Components of EECP. The chemical constituents of EECP were measured by HPLC-DAD/QTOF-MS analysis, and a total of 16 constituents were identified and quantified (Table 2). Flavonoids such as chrysin, pinocembrin, pinobanksin, apigenin, galangin, and quercin 
TABLE 2: The chemical constituents of EECP identified by HPLCDAD/Q-TOF-MS analysis.

\begin{tabular}{lccc}
\hline Compounds & $\mathrm{M}+\mathrm{H}$ & $\mathrm{RT}$ & Content $(\mathrm{mg} / \mathrm{g})$ \\
\hline Chrysin & 255.0652 & 31.264 & 16.887 \\
Pinocembrin & 257.0808 & 30.431 & 15.243 \\
Pinobanksin & 273.0757 & 27.11 & 6.879 \\
Apigenin & 271.0601 & 28.781 & 4.552 \\
Galangin & 271.0601 & 31.521 & 23.538 \\
Kaempferol & 287.0550 & 28.418 & 3.321 \\
Quercin & 303.0499 & 26.811 & 1.229 \\
Caffeic acid & 181.0495 & 17.172 & 10.857 \\
Gallic acid & 171.0288 & 26.392 & 0.470 \\
p-Coumaric acid & 165.0546 & 20.232 & 4.369 \\
3-O-Acetyl pinobanksin & 315.0863 & 30.708 & 15.570 \\
Naringin & 273.0612 & 27.11 & 6.876 \\
Ferulic acid & 195.0652 & 21.391 & 1.567 \\
3,4-Dimethoxycinnamic acid & 209.0808 & 24.676 & 9.945 \\
Trans-cinnamic acid & 195.0652 & 21.391 & 6.222 \\
Caffeic acid phenethyl ester & 285.1121 & 31.273 & 2.851 \\
\hline
\end{tabular}

were rich in EECP, and previous studies also showed that these compounds have excellent antitumor activities [21-25].

3.2. EECP Decreased Cell Viability in MDA-MB-231 Cells Stimulated with LPS. To investigate the antiproliferation activity of $\operatorname{EECP}(25,50$, and $100 \mu \mathrm{g} / \mathrm{mL})$ in MDA-MB-231 cells stimulated with LPS, the cell viabilities at 12,24 , and $48 \mathrm{~h}$ were firstly tested using a CCK-8 kit. As shown in Figure 1, there was dramatic decrease in cell viabilities after treatment with different concentrations of EECP, and EECP was found to inhibit MDA-MB-231 cell proliferation in a time- and dose-dependent manner when compared with the LPS group. There was no significant different in cell viabilities between the control and LPS groups $\left({ }^{*} P<0.05,{ }^{* *} P\right.$ $<0.01$; Figures 1(a)-1(c)).

3.3. EECP Suppressed Migration, Invasion, and Colony Formation in MDA-MB-231 Cells Stimulated with LPS. To further confirm the effect of EECP on the migration, invasion, and clone formation of MDA-MB-231 cells stimulated with LPS, a transwell experiment and angiogenesis assay were performed. In comparison with the control and LPS groups, treatment with different concentrations of EECP obviously suppressed the cell migration and invasiveness of MDA-MB-231 cells stimulated with LPS. Pretreatment with different concentrations of EECP also dramatically decreased the numbers of colonies formed compared with the LPS group $\left({ }^{*} P<0.05,{ }^{* *} P<0.01\right.$; Figures $\left.2(\mathrm{a})-(\mathrm{d})\right)$.

3.4. EECP Inhibited Endothelial Cell Tube Formation. Tumor associated angiogenesis plays a crucial role in the growth and metastasis of tumor [26]. To determine the effect of EECP on angiogenesis in vitro, HUVECs were treated with different concentrations of $\operatorname{EECP}(25,50$, and $100 \mu \mathrm{g} / \mathrm{mL})$ for $6 \mathrm{~h}$. Compared with the LPS group, endothelial cell tube forma- tion abilities were significantly decreased after treatment with EECP. Correspondingly, the numbers of tubes and tube branches were significantly decreased in a dose-dependent manner after EECP treatment, suggesting that EECP probably inhibits tumor angiogenesis $\left({ }^{*} P<0.05,{ }^{* *} P<0.01\right.$; Figures 2(e)-(g)).

3.5. EECP Suppressed the Levels of Inflammatory Mediators in MDA-MB-231 Cells Stimulated with LPS. The levels of IL-6, IL- $1 \beta$, and TNF- $\alpha$ in the LPS groups were evidently increased. Treatment with EECP resulted in a decrease in these proinflammatory cytokines when compared with the LPS group (Figures 3(a)-3(c)). Furthermore, a decrease in the production of IL- $1 \beta$ was also demonstrated by RT-PCR (Figure 3(d)). More importantly, treatment with a higher concentration of EECP significantly reversed the increase of NLRP3, as shown by Western blotting analysis (Figures 3(e) and 3(f)).

3.6. EECP Decreased the Levels of HK2, PFK, PKM2, and LDHA in MDA-MB-231 Cells Stimulated with LPS. The levels of the key enzymes of glycolysis-HK2, PFK, PKM2, and LDHA - in MDA-MB-231 cells stimulated with LPS were firstly measured using ELISA kits. The levels of HK2, PFK, PKM2, and LDHA after EECP treatment were obviously decreased compared with the LPS group, especially after treatment with a higher concentration of EECP (Figures 4(a)-4(d)).

The decrease in the levels of HK2, PFK, PKM2, and LDHA in MDA-MB-231 cells stimulated with LPS was further confirmed by RT-PCR (Figures 4(e)-4(h)). As expected, EECP treatment dramatically decreased the mRNA levels of HK2, PFK, PKM2, and LDHA in a dose-dependent manner compared with the LPS group.

The protein expression levels of HK2, PFK, PKM2, and LDHA in MDA-MB-231 cells stimulated with LPS were also assessed. As shown in Figures 5(a)-5(e), it was observed that expression levels of the key enzymes of glycolysis were downregulated in the EECP treatment groups compared with the LPS group. The EECP administration alleviated glycolysis by suppressing the levels of $\mathrm{HK} 2$, PFK, PKM2, and LDHA.

The immunofluorescence assay of PKM2 and LDHA further confirmed that the EECP administration suppressed the protein expression of PKM2 and LDHA in MDA-MB-231 cells stimulated with LPS. The fluorescence intensities of PKM2 and LDHA evidently decreased in EECP treatment groups compared with the LPS group $\left({ }^{*} P<0.05,{ }^{* *} P<0.01\right.$; Figures 5(f)-5(h)).

3.7. EECP Increased ROS Production and Decreased Mitochondrial Membrane Potential in MDA-MB-231 Cells Stimulated with LPS. Mitochondria are the center of energy and metabolism in eukaryons. They are also cellular organs with a critical adjusting function in apoptosis signaling processes. To determine the effect of EECP on mitochondria, the mitochondrial membrane potential and ROS production were analyzed. The functions of mitochondria were damaged, and ROS production was obviously increased after 


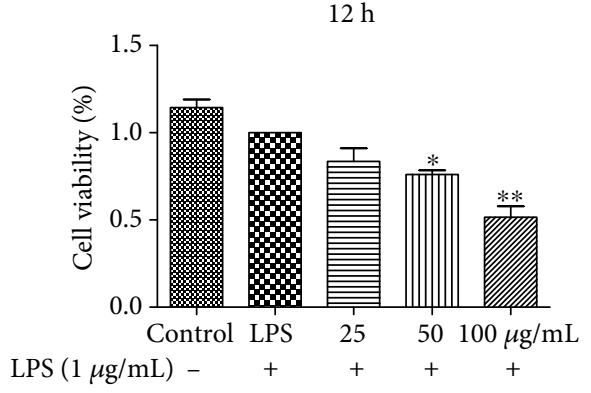

(a)

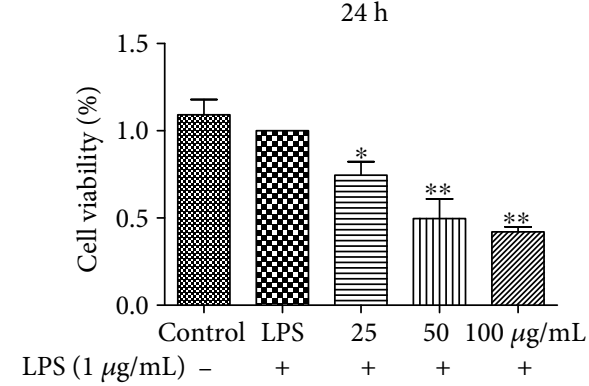

(b)

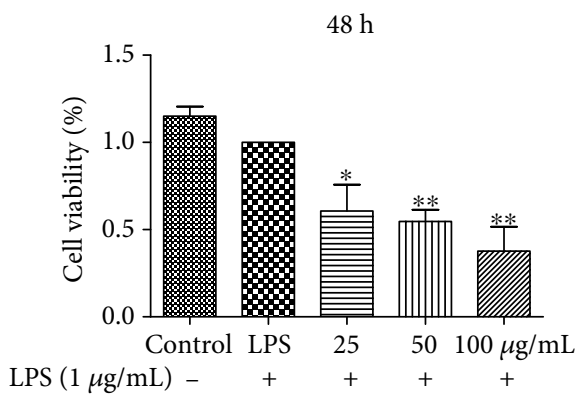

(c)

FIgure 1: EECP decreased cell viability in MDA-MB-231 cells stimulated with lipopolysaccharide (LPS). (a)-(c) Effect of EECP on the cell viability of MDA-MB-231 cells stimulated with LPS at 12, 24, and $48 \mathrm{~h}$, respectively. 25,50 , and $100 \mu \mathrm{g} / \mathrm{mL}$ : cells treated with EECP at 25,50 , and $100 \mu \mathrm{g} / \mathrm{mL}$, respectively. Values represent the mean \pm SEM from three independent experiments $\left({ }^{*} P<0.05,{ }^{* *} P<0.01\right.$ vs. control, $\left.n=3\right)$.

EECP treatment with the LPS group in MDA-MB-231 cells stimulated with LPS $\left({ }^{*} P<0.05,{ }^{* *} P<0.01\right.$; Figures $6(\mathrm{a})-$ $6(\mathrm{c}))$.

3.8. EECP Inhibited MDA-MB-231 Cell Migration in a Glycolysis-Dependent Manner. To confirm whether EECP inhibited MDA-MB-231 cell migration through inhibiting glycolysis, the scratching assay was performed by adding 2deoxy-D-glucose (2-DG) into cells. EECP significantly suppressed MDA-MB-231 cell migration without 2-DG in the medium. However, the inhibitory effects in EECP groups were not significant compared with the LPS group after adding 2-DG into the medium, suggesting that EECP's exhibitory effects on MDA-MB-231 cells were probably via the glycolysis pathway $\left({ }^{*} P<0.05, \quad{ }^{* *} P<0.01\right.$; Figures $7(\mathrm{a})$ and $7(\mathrm{~b}))$.

\section{Discussion}

Although propolis has been shown to have excellent antitumor activities, previous studies assessing antitumor mechanisms by targeting key enzymes of glycolysis were limited. In the present study, we evaluated the antitumor mechanisms of Chinese populus propolis in MDA-MB-231 cells stimulated with LPS by studying key glycolysis-related enzymes: HK2, PFK, PKM2, and LDHA. Propolis treatment was able to inhibit MDA-MB-231 cells proliferation, migration, invasion, and angiogenesis, as well as suppress the production of proinflammatory cytokines. More importantly, propolis treatment obviously inhibited the levels of HK2, PFK, PKM2, and LDHA.
The incidence of $\mathrm{BC}$ has grown rapidly in recent years. $\mathrm{BC}$ can severely decrease a patient's quality of life and has high lethality in women. Tumor glycolysis is crucial for the efficient management of cellular bioenergetics and uninterrupted cancer growth [27]. Although glycolysis is less efficient than oxidative phosphorylation in terms of the net yield of ATP, cancer cells adapt to this mathematical disadvantage by increased glucose uptake, which in turn facilitates a higher rate of glycolysis. Glycolysis in tumor cells produces pyruvate, which is converted to lactic acid in the cytoplasm. These acidic products alter the microenvironment to accelerate tumor proliferation, migration, invasion, and angiogenesis and instigate immunosuppressive networks that are pivotal for cancer cells to escapes immune surveillance [28]. Multiple lines of evidence have established that higher expression levels of key enzymes such as HK2, PFK, PKM2, and LDHA are linked to malignant growth $[29,30]$. Thus, targeting glycolysis remains an attractive strategy for therapeutic intervention.

HK catalyzes the first step in glucose metabolism converting glucose to glucose-6-phosphate [29]. HK2 status is clinically linked to recurrence and poor prognosis in $\mathrm{BC}$ [31]. This enzyme plays a pivotal role in tumor glycolysis. Inhibition of HK2 has been shown to inhibit the proliferation of cancer cells by shifting the glycolytic pathway with reduced lactate formation [32]. Here, the levels of HK2 were significantly decreased in MDA-MB-231 cells after propolis treatment, as determined by multiple measurement methods.

$\mathrm{PFK}$ is crucial in BC cancer progression and is also upregulated in cancer cells; it catalyzes another rate-limiting step of glycolysis, from fructose-6-phosphate to fructose-1,6bisphosphate [33]. Consistent with the results for HK2, 


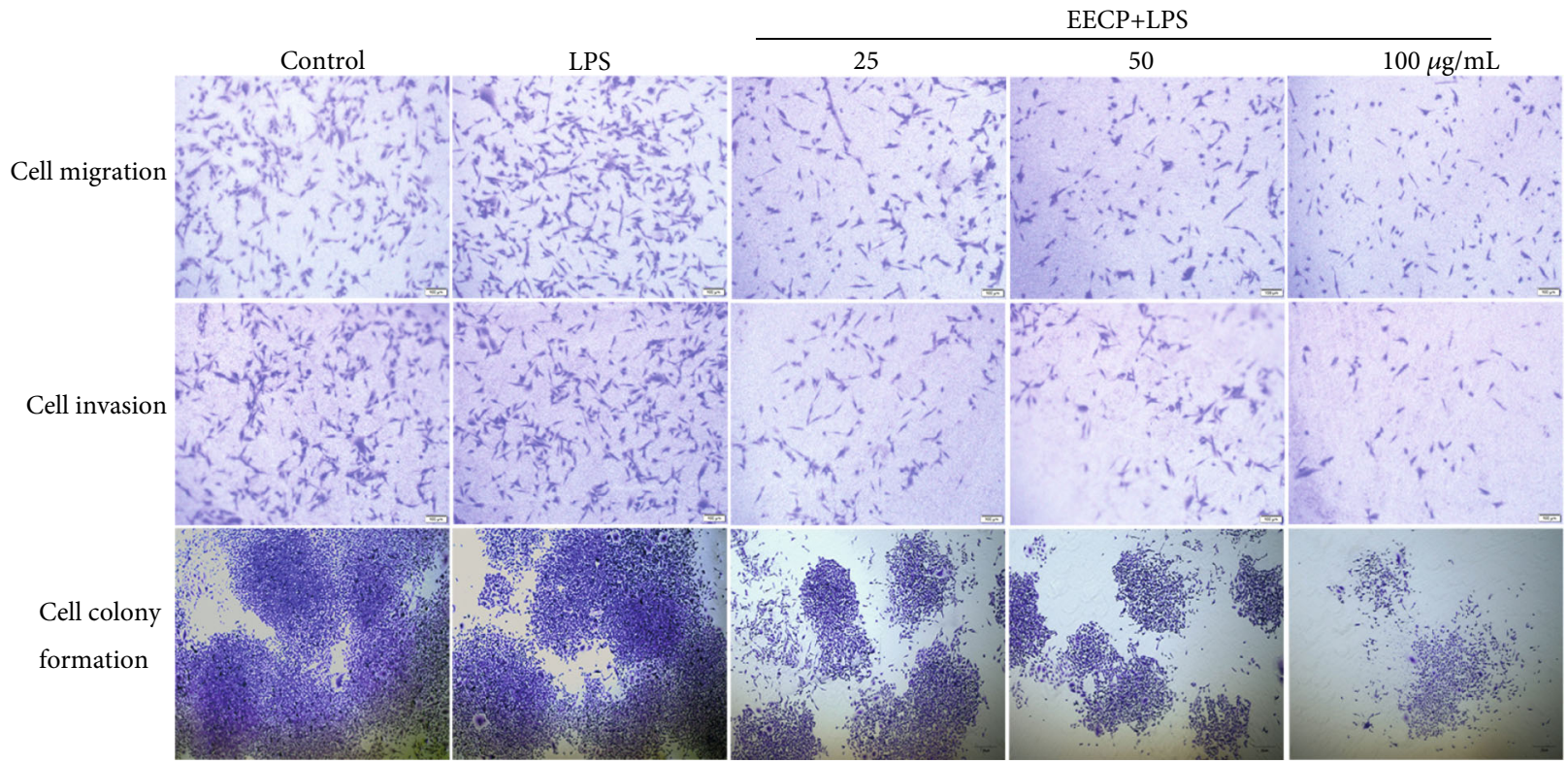

(a)

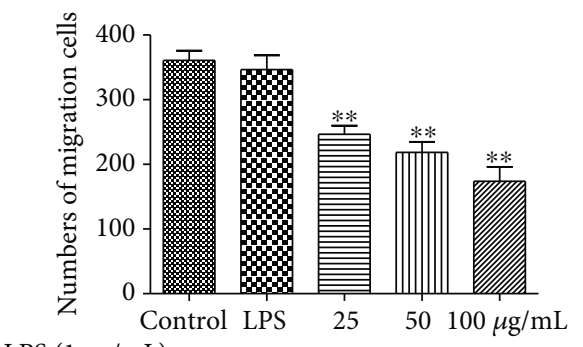
LPS $(1 \mu \mathrm{g} / \mathrm{mL})-$

(b)

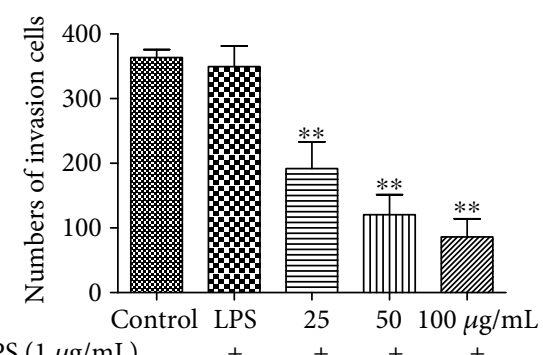

(c)

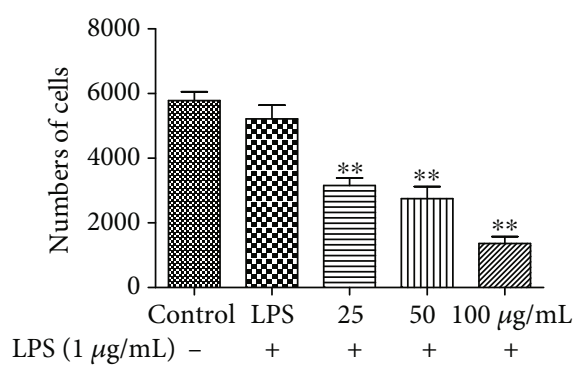

(d)
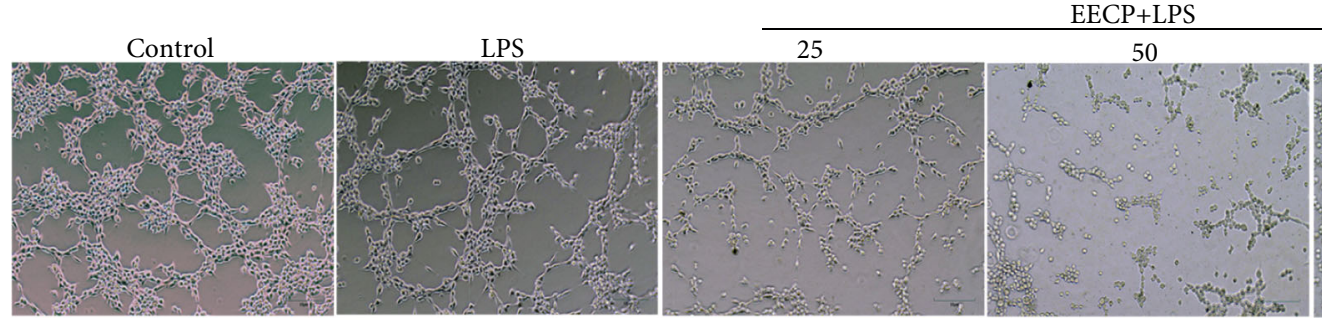

$100 \mu \mathrm{g} / \mathrm{mL}$

(e)

Figure 2: Continued. 


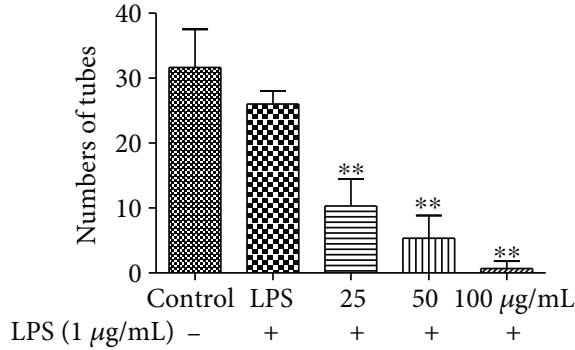

(f)

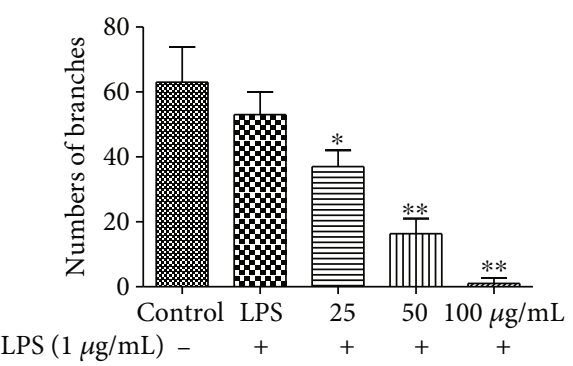

(g)

FIgURE 2: EECP suppressed migration, invasion, and colony formation in MDA-MB-231 cells stimulated with LPS. (a) EECP suppressed migration, invasion, and colony formation in MDA-MB-231 cells. (b)-(d) Quantification of cell migration, invasion, and colony formation in MDA-MB-231 cells after EECP treatment. (e) EECP inhibited angiogenesis in human umbilical vein endothelial cells (HUVECs) at $6 \mathrm{~h}$. (f, g) Quantification of tubes and branches of angiogenesis. Values represent the mean \pm SEM from three independent experiments $\left({ }^{*} P<0.05,{ }^{* *} P<0.01\right.$ vs. control, $\left.n=3\right)$.

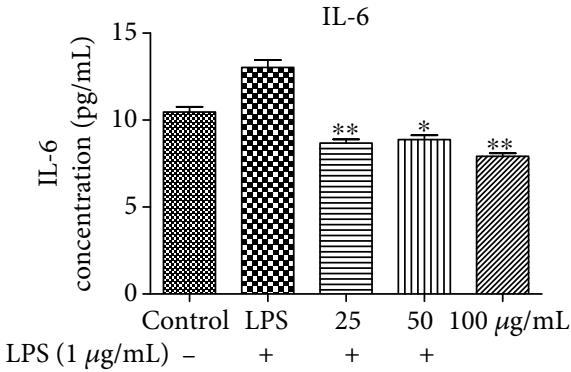

(a)

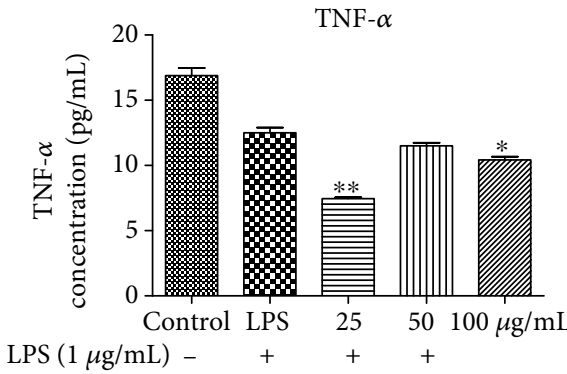

(c)

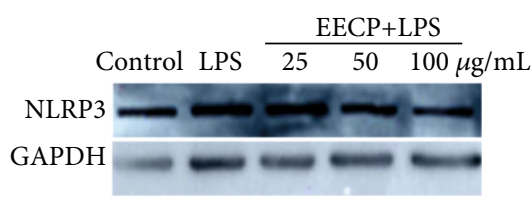

(e)

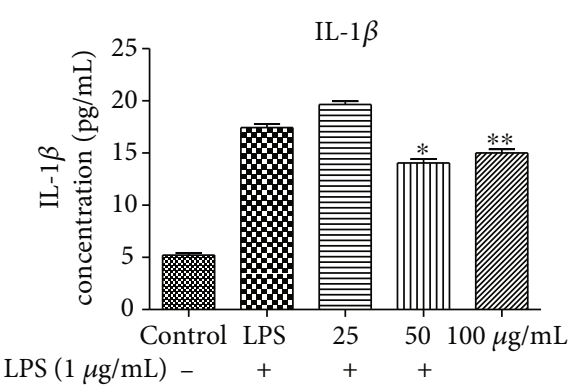

(b)

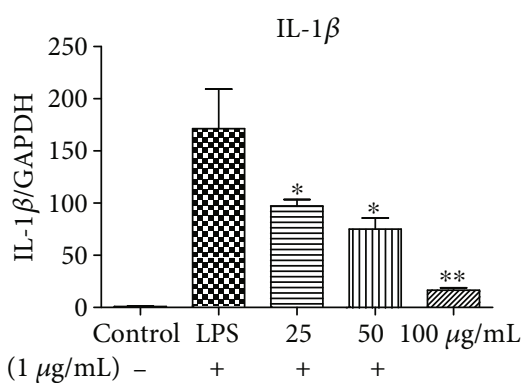

(d)

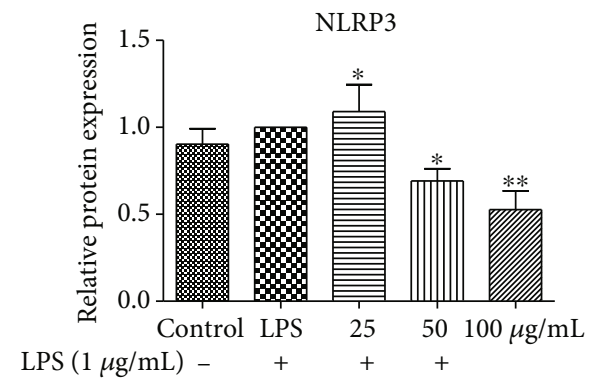

(f)

Figure 3: EECP suppressed the levels of inflammatory mediators in MDA-MB-231 cells stimulated with LPS. (a)-(c) EECP inhibited the levels of IL-6, IL- $1 \beta$, and TNF- $\alpha$ in MDA-MB-231 cells stimulated with LPS, as detected by ELISA kits. (d) EECP inhibited the levels of IL- $1 \beta$ compared with the LPS group, as detected by RT-PCR. (e) EECP inhibited the levels of NLRP3 compared with the LPS group, as detected by Western blotting. (f) Quantification of the relative expression level of NLRP3 in MDA-MB-231 cells. Values represent the mean \pm SEM from three independent experiments $\left({ }^{*} P<0.05,{ }^{* *} P<0.01\right.$ vs. control, $\left.n=3\right)$. 


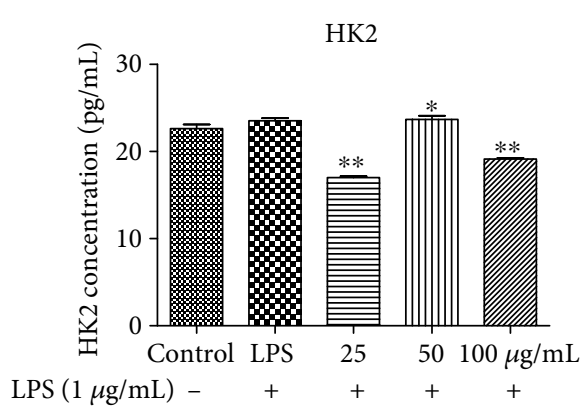

(a)

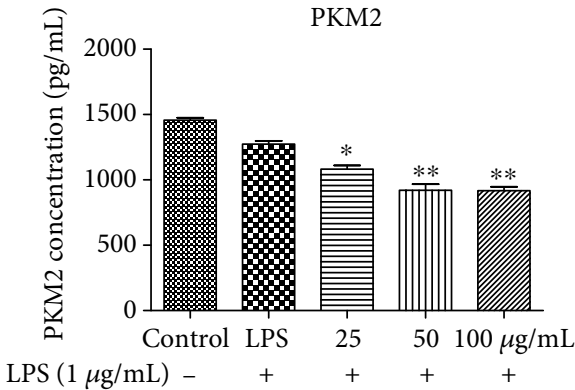

(c)

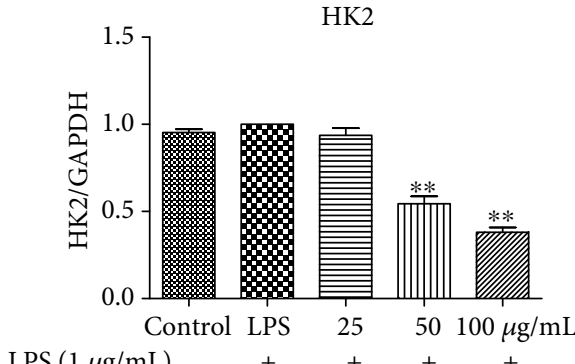

(e)

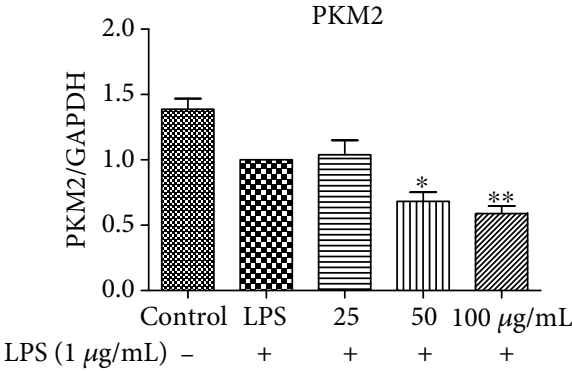

(g)

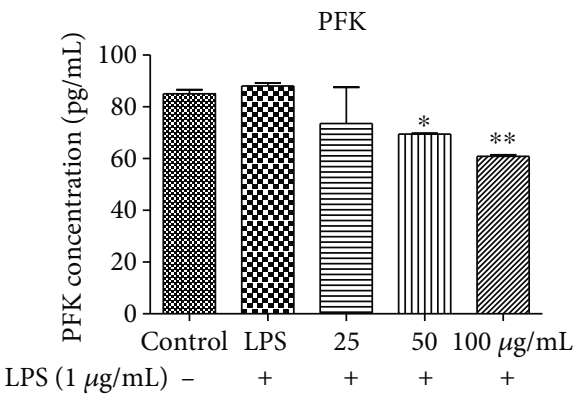

(b)

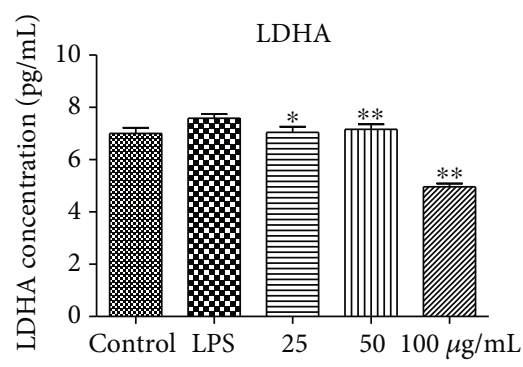

(d)

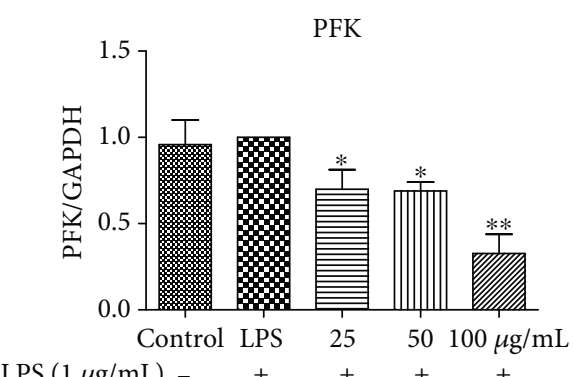

(f)

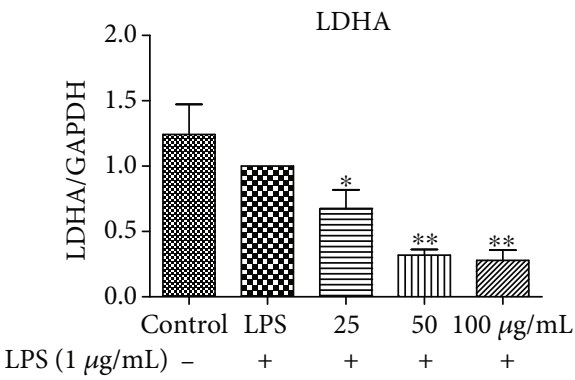

(h)

Figure 4: EECP decreased the levels of HK2, PFK, PKM2, and LDHA in MDA-MB-231 cells stimulated with LPS. (a)-(d) EECP decreased the levels of HK2, PFK, PKM2, and LDHA in MDA-MB-231 cells, as detected by ELISA kits. (e)-(h) EECP decreased the levels of HK2, PFK, PKM2, and LDHA in MDA-MB-231 cells, as detected by RT-PCR. Values represent the mean \pm SEM from three independent experiments $\left({ }^{*} P<0.05,{ }^{* *} P<0.01\right.$ vs. control, $\left.n=3\right)$.

propolis treatment obviously suppressed the levels of PFK, suggesting that propolis could target key glycolytic enzymes.

PK catalyzes the conversion of phosphoenolpyruvate (PEP) to pyruvate. Among its various isoforms, the M2 isoform has gained much attention due to its higher expression in tumor cells [34]. PKM2 is crucial for aerobic glycolysis and tumor energy metabolism [35]. Emerging preclinical studies have indicated that PKM2 could represent a potential thera- peutic target [36]. Here, we also demonstrated that propolis treatment alleviated the levels of PKM2.

LDH catalyzes the final step in the glycolytic pathway that converts pyruvate into lactate, and a higher lactate level significantly correlates with tumor recurrence and the metastatic potential of tumors resulting in poor patient outcomes [37]. Besides this, several studies have identified a prominent role of LDHA in TNBCs [38]. Propolis significantly inhibited 


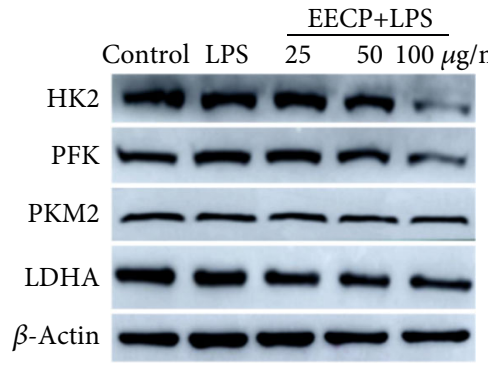

(a)

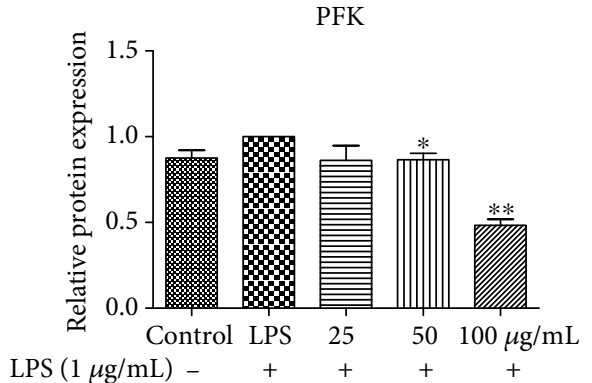

(c)
HK2

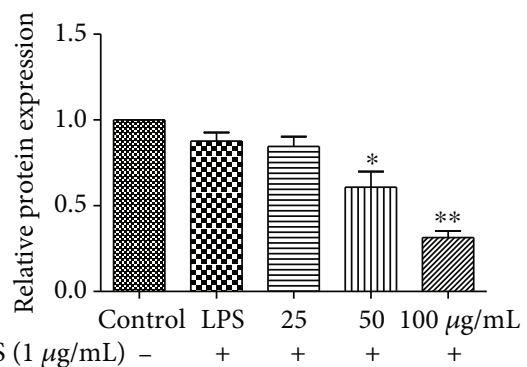

(b)

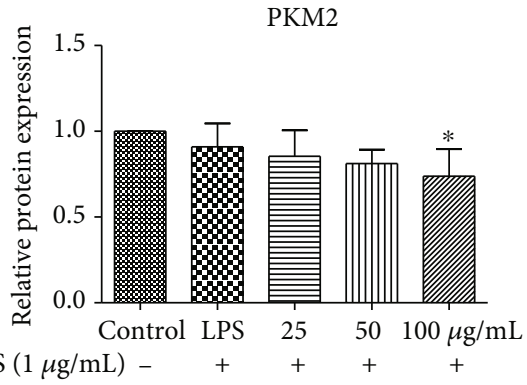

(d)

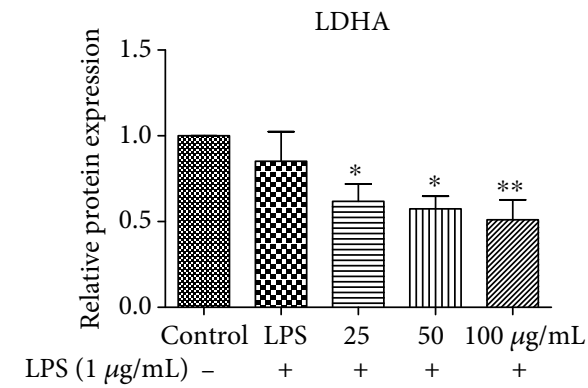

(e)

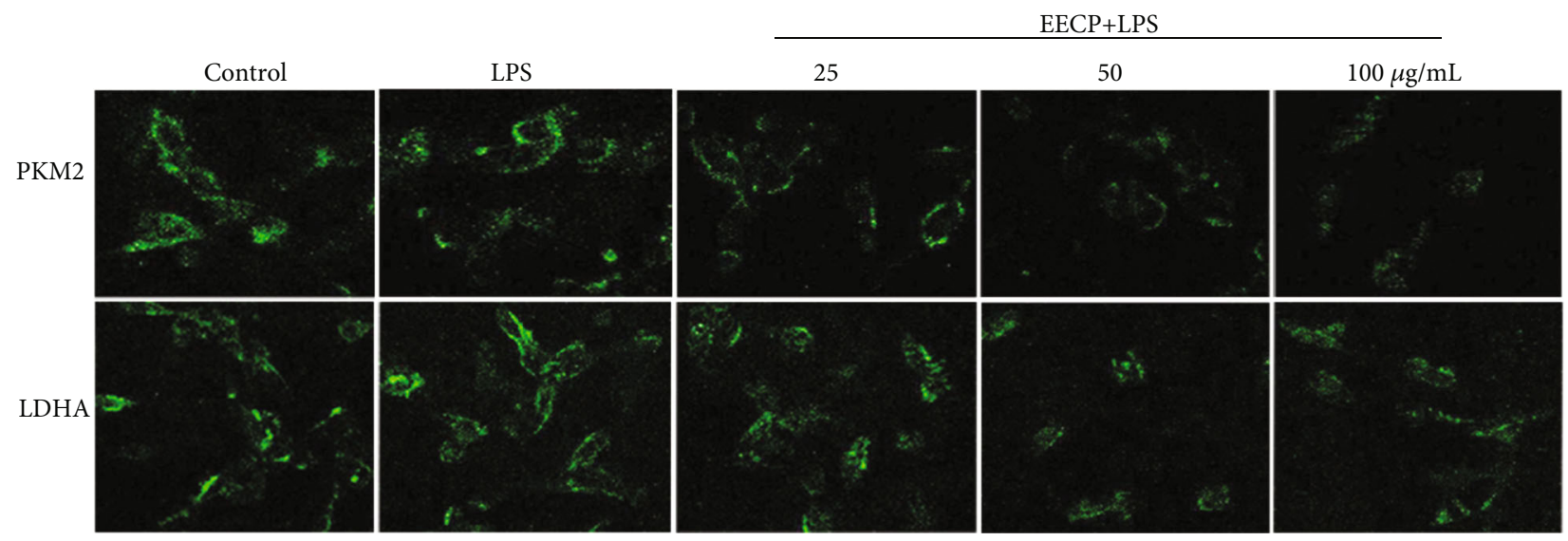

(f)

Figure 5: Continued. 


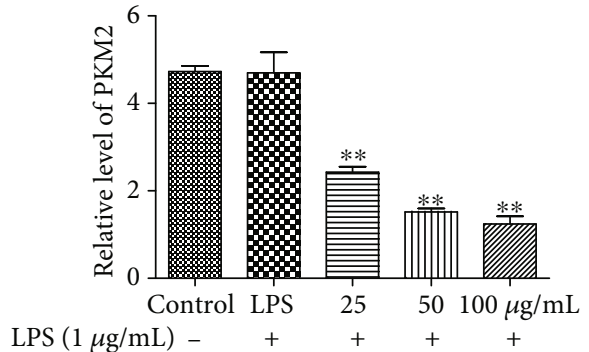

(g)

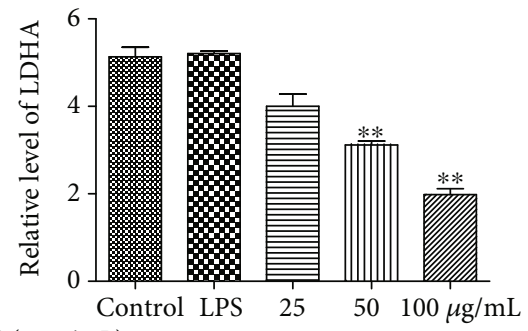

LPS $(1 \mu \mathrm{g} / \mathrm{mL})$

(h)

Figure 5: EECP decreased the levels of HK2, PFK, PKM2, and LDHA in MDA-MB-231 cells stimulated with LPS, as detected by Western blotting and immunofluorescence assay. (a) The protein expression levels of HK2, PFK, PKM2, and LDHA in MDA-MB-231 cells. (b)-(e) Quantification of the relative expression levels of HK2, PFK, PKM2, and LDHA in MDA-MB-231 cells. (f) Expression levels of PKM2 and LDHA, as detected by the immunofluorescence assay. $(\mathrm{g}, \mathrm{h})$ Quantification of the relative expression levels of PKM2 and LDHA in MDAMB-231 cells. Values represent the mean \pm SEM from three independent experiments $\left({ }^{*} P<0.05,{ }^{* *} P<0.01\right.$ vs. control, $\left.n=3\right)$.

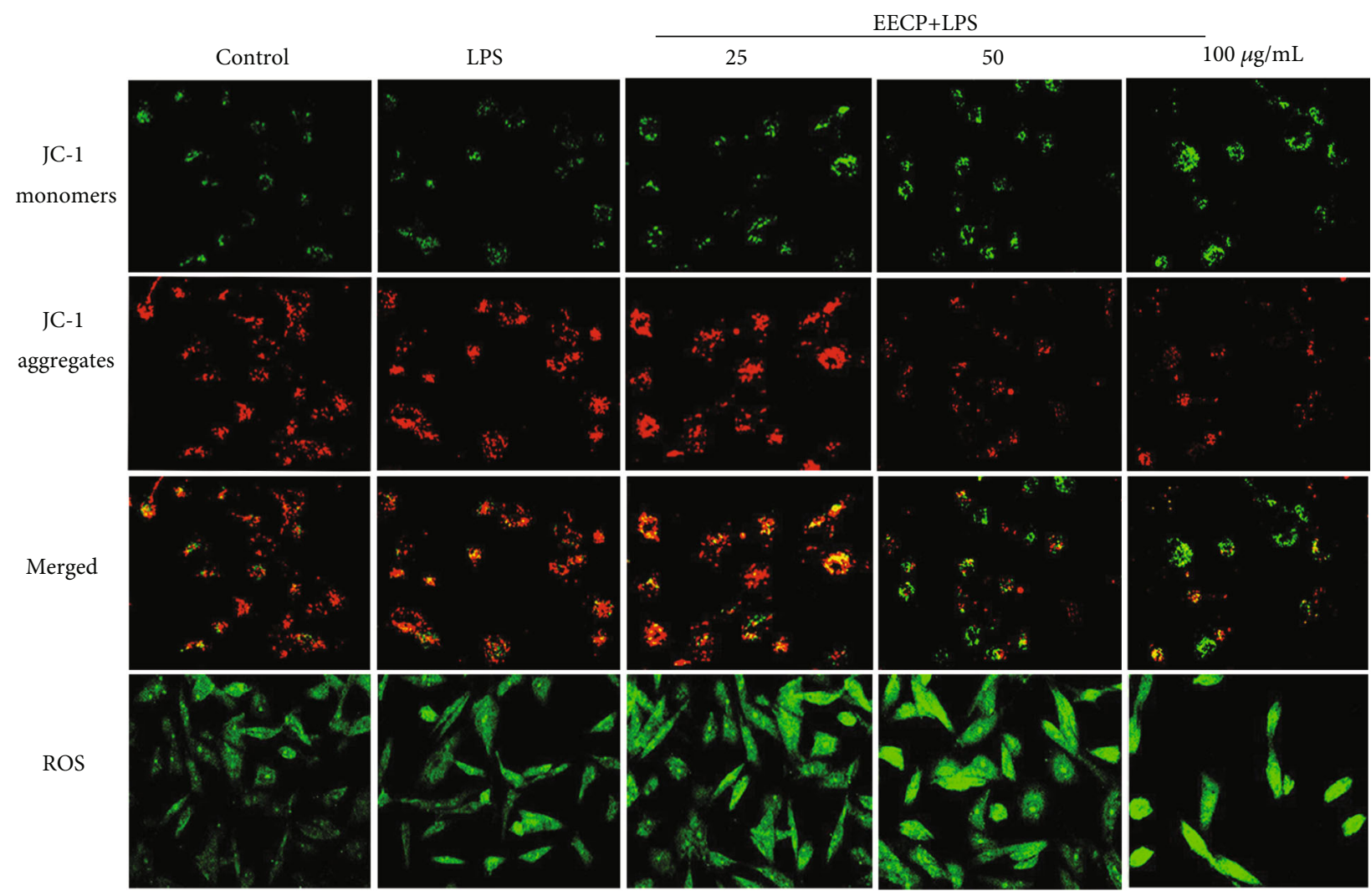

(a)

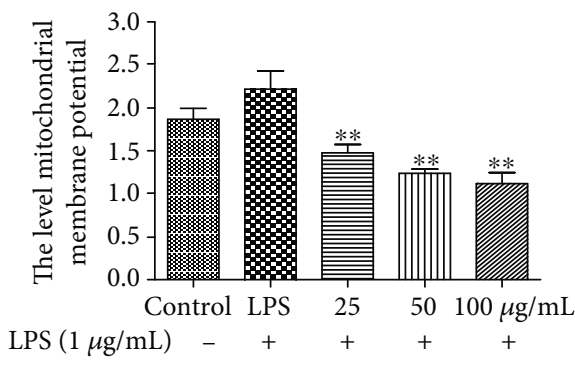

(b)

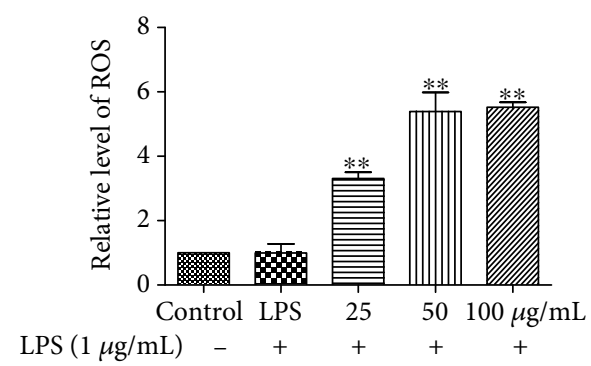

(c)

FIGURE 6: EECP increased reactive oxygen species (ROS) levels and decreased mitochondrial membrane potential in MDA-MB-231 cells stimulated with LPS. (A) Fluorescence micrographs obtained at $24 \mathrm{~h}$. (b, c) Values represent the relative fluorescence intensity per cell determined by laser scanning confocal microscopy. Values represent the mean \pm SEM from three independent experiments $\left({ }^{*} P<0.05^{* *} P<0.01\right.$, vs. control, $\left.n=3\right)$. 


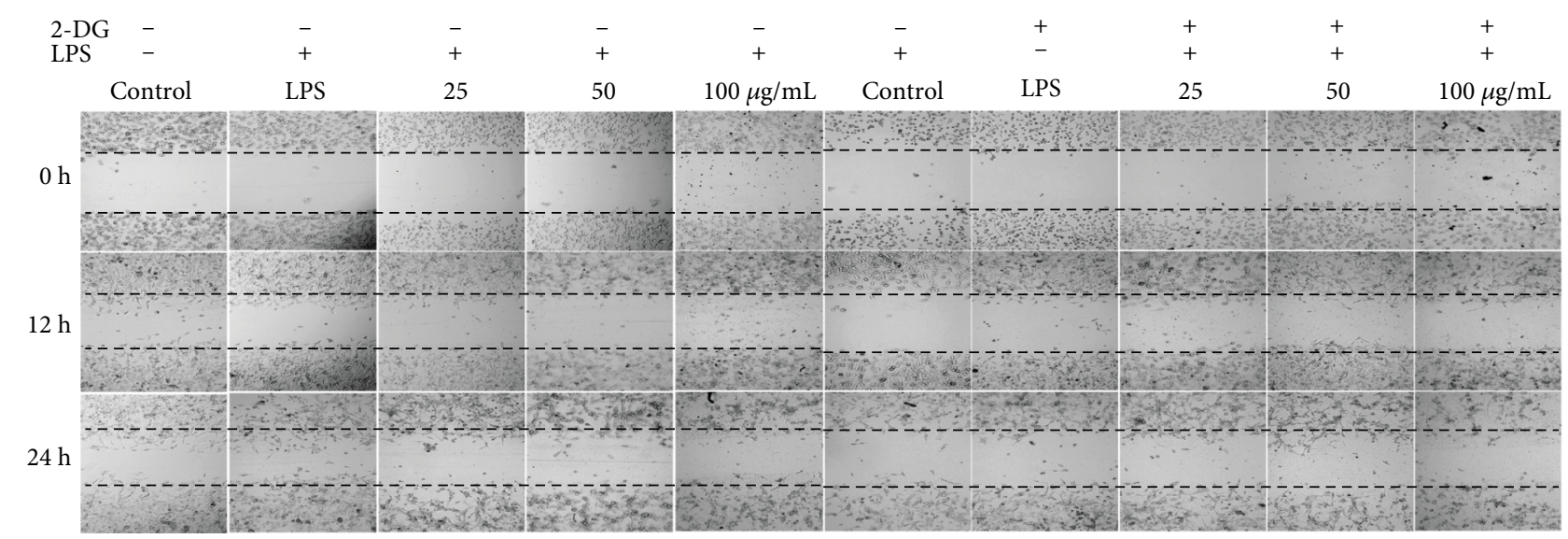

(a)

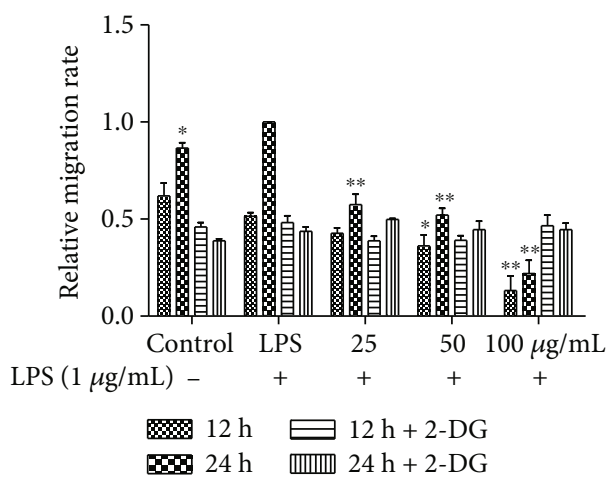

(b)

FIGURE 7: EECP inhibited MDA-MB-231 cell migration in a glycolysis-dependent manner. (a) Effect of EECP on the migration of MDA-MB231 cells stimulated with LPS with or without 2-deoxy-D-glucose (2-DG). (b) Quantification of the relative migration rate of MDA-MB-231 cells. Values represent the mean \pm SEM from three independent experiments $\left({ }^{*} P<0.05,{ }^{* *} P<0.01\right.$ vs. control, $\left.n=3\right)$.

the levels of LDHA, demonstrating promising effects in the prevention of TNBCs.

2-DG, a glucose analog, inhibits glycolysis via its actions on hexokinase [39]. We used 2-DG to inhibit glycolysis in MDA-MB-231 cells to assess the effects of propolis. The results showed that propolis treatment no longer inhibited MDA-MB-231 cell migration compared with the LPS group after inhibition of glycolysis, indicating that propolis exerts the antitumor activity by targeting glycolysis.

ROS are a key determinant of cancer's metabolic phenotype [40]. Maintaining ROS within a narrow range allows malignant cancer cells to enhance their growth and invasion while limiting their apoptotic susceptibility [41]. Cancer cells actively modify their metabolism to optimize intracellular ROS levels and thereby improve survival [42]. Propolis treatment evidently increased the ROS level and decreased the mitochondrial membrane potential in MDA-MB-231 cells stimulated with LPS. The present results are consistent with our original findings, indicating that propolis increases the ROS level to promote cancer cells apoptosis.

The inhibition of glycolysis can also transform tumor cells into forms that are sensitive to immunotherapy and can alter the tumor microenvironment [43]. The NLRP3 inflamma- some can be activated by various danger-associated molecular patterns, and the activation of NLPR 3 induces caspase- 1 activation, IL- $1 \beta$ or IL-18 secretion, and pyroptosis [44]. It has been shown that NLRP3 inflammasome activation in the tumor microenvironment has a critical role in the response to some chemotherapeutic agents [45]. Propolis has excellent anti-inflammatory and immune regulation activities [10]. Here, we also demonstrated that propolis decreased the levels of proinflammatory mediators, including TNF- $\alpha$, IL- $1 \beta$, and IL-6, as well as NLRP3 inflammasome to improve the tumor inflammatory microenvironment.

Propolis is rich in flavonoids such as chrysin, pinocembrin, pinobanksin, apigenin, galangin, and quercin, and previous studies also showed that these compounds have excellent antitumor activities. Besides these, CAPE, one of the most important constituent of propolis, also has a strong antitumor activity. In all, these antitumor constituents in propolis account for the strong antitumor activities of propolis.

There are still some limitations in our study. First, although propolis has significant inhibitory effects on glycolytic key enzymes in MDA-MB-231 cells, the effects of propolis on these key enzymes in other tumor cell lines should be 
further demonstrated. Second, whether propolis attenuating glycolytic key enzymes suppresses the tumor growth signaling pathway such as PI3K-Akt or propolis inhibiting the PI3K-Akt signaling pathway attenuates glycolytic key enzymes should be further studied.

\section{Conclusions}

Taken together, the results of this study show that propolis treatment of MDA-MB-231 cells in an inflammatory microenvironment was able to inhibit tumor cell proliferation by targeting key enzymes of glycolysis. As a natural product rich in flavonoids, propolis demonstrated good anti-inflammatory activity in the tumor microenvironment by inhibiting inflammatory cytokines. It was also noted that propolis could target key enzymes of glycolysis to suppress proliferation, migration, invasion, and angiogenesis. Moreover, it was demonstrated that propolis could damage the mitochondrial function by decreasing the mitochondrial membrane potential and increasing ROS production. As a result, Chinese populus propolis has excellent potential for use in the prevention and treatment of BC.

\section{Abbreviations}

$\begin{array}{ll}\text { BC: } & \text { Breast cancer } \\ \text { EECP: } & \text { Ethanol extract of Chinese propolis } \\ \text { FBS: } & \text { Fetal bovine serum } \\ \text { HK2: } & \text { Hexokinase } 2 \\ \text { HUVECs: } & \text { Human umbilical vein endothelial cells } \\ \text { IL-1 } \beta \text { : } & \text { Interleukin-1 } \beta \\ \text { LDHA: } & \text { Lactate dehydrogenase A } \\ \text { LPS: } & \text { Lipopolysaccharide } \\ \text { PFK: } & \text { Phosphate fructose kinase } \\ \text { PKM2: } & \text { Pyruvate kinase muscle isozyme M2 } \\ \text { PVDF: } & \text { Polyvinylidene difluoride } \\ \text { ROS: } & \text { Reactive oxygen species } \\ \text { SDS-PAGE: } & \text { Sodium dodecyl sulfate polyacrylamide gel } \\ & \text { electrophoresis } \\ \text { TNBC: } & \text { Triple-negative breast cancer } \\ \text { TNF- } \alpha: & \text { Tumor necrosis factor-alpha. }\end{array}$

\section{Data Availability}

The data used to support the findings of this study are included within the article.

\section{Conflicts of Interest}

The authors declare no competing conflicts of interest.

\section{Authors' Contributions}

H.Z. Xuan and S.Y. Hao designed the study and wrote the manuscript. Y. Jun, H. Liu, and Z.H. Zhang conducted the experiments and analyzed the data. X.Y. Liu and S.Y. Hao revised the manuscript. Y. Jun and H. Liu contributed equally to this work.

\section{Acknowledgments}

This work was supported by the grant from the National Natural Science Foundation of China (No. 31672499) and Shandong Province Modern Agricultural Technology System (SDAIT-24-05).

\section{References}

[1] O. Golubnitschaja, M. Debald, K. Yeghiazaryan et al., "Breast cancer epidemic in the early twenty-first century: evaluation of risk factors, cumulative questionnaires and recommendations for preventive measures," Tumour Biology, vol. 37, no. 10, pp. 12941-12957, 2016.

[2] G. A. Burdock, "Review of the biological properties and toxicity of bee propolis (propolis)," Food and Chemical Toxicology, vol. 36, no. 4, pp. 347-363, 1998.

[3] V. Bankova, "Chemical diversity of propolis and the problem of standardization," Journal of Ethnopharmacology, vol. 100, no. 1-2, pp. 114-117, 2005.

[4] S. Huang, C. P. Zhang, K. Wang, G. Q. Li, and F. L. Hu, "Recent advances in the chemical composition of propolis," Molecules, vol. 19, no. 12, pp. 19610-19632, 2014.

[5] M. C. Fernandez-Calderon, M. L. Navarro-Perez, M. T. Blanco-Roca, C. Gomez-Navia, C. Perez-Giraldo, and V. Vadillo-Rodriguez, "Chemical profile and antibacterial activity of a novel Spanish propolis with new polyphenols also found in olive oil and high amounts of flavonoids," Molecules, vol. 25, no. 15, article 3318, 2020.

[6] H. Xuan, Y. Wang, A. Li, C. Fu, and W. Peng, "Bioactive components of Chinese propolis water extract on antitumor activity and quality control," Evidence-Based Complementary and Alternative Medicine, vol. 2016, Article ID 9641965, 9 pages, 2016.

[7] V. Bankova, A. S. Galabov, D. Antonova, N. Vilhelmova, and B. Di Perri, "Chemical composition of propolis extract $\mathrm{ACF}^{\circledR}$ and activity against herpes simplex virus," Phytomedicine, vol. 21, no. 11, pp. 1432-1438, 2014.

[8] Y. Zheng, Y. Wu, X. Chen, X. Jiang, K. Wang, and F. Hu, "Chinese propolis exerts anti-proliferation effects in human melanoma cells by targeting NLRP1 inflammatory pathway, inducing apoptosis, cell cycle arrest, and autophagy," Nutrients, vol. 10, no. 9, article 1170, 2018.

[9] Y. Z. Zheng, G. Deng, Q. Liang, D. F. Chen, R. Guo, and R. C. Lai, "Antioxidant activity of quercetin and its glucosides from propolis: a theoretical study," Scientific Reports, vol. 7, no. 1, article 7543, 2017.

[10] J. M. Sforcin, "Propolis and the immune system: a review," Journal of Ethnopharmacology, vol. 113, no. 1, pp. 1-14, 2007.

[11] K. Wang, J. Zhang, S. Ping et al., “Anti-inflammatory effects of ethanol extracts of Chinese propolis and buds from poplar (Populus $\times$ canadensis)," Journal of Ethnopharmacology, vol. 155, no. 1, pp. 300-311, 2014.

[12] H. Chang, Y. Wang, X. Yin, X. Liu, and H. Xuan, "Ethanol extract of propolis and its constituent caffeic acid phenethyl ester inhibit breast cancer cells proliferation in inflammatory microenvironment by inhibiting TLR4 signal pathway and inducing apoptosis and autophagy," BMC Complementary and Alternative Medicine, vol. 17, no. 1, article 471, 2017.

[13] R. Li, P. Li, J. Wang, and J. Liu, "STIP1 down-regulation inhibits glycolysis by suppressing PKM2 and LDHA and 
inactivating the Wnt/beta-catenin pathway in cervical carcinoma cells," Life Sciences, vol. 258, article 118190, 2020.

[14] X. Li, J. Sun, Q. Xu et al., "Oxymatrine inhibits colorectal cancer metastasis via attenuating PKM2-mediated aerobic glycolysis," Cancer Management and Research, vol. Volume 12, pp. 9503-9513, 2020.

[15] N. Lang, C. Wang, J. Zhao, F. Shi, T. Wu, and H. Cao, "Long non-coding RNA BCYRN1 promotes glycolysis and tumor progression by regulating the miR-149/PKM2 axis in non-small-cell lung cancer," Molecular Medicine Reports, vol. 21, no. 3, pp. 1509-1516, 2020.

[16] M. Katagiri, H. Karasawa, K. Takagi et al., "Hexokinase 2 in colorectal cancer: a potent prognostic factor associated with glycolysis, proliferation and migration," Histology and Histopathology, vol. 32, no. 4, pp. 351-360, 2017.

[17] E. E. Hackett, H. Charles-Messance, S. M. O'Leary et al., "Mycobacterium tuberculosis limits host glycolysis and IL-1 $\beta$ by restriction of PFK-M via MicroRNA-21," Cell Reports, vol. 30, no. 1, pp. 124-136.e4, 2020.

[18] R. Ren, J. Guo, J. Shi, Y. Tian, M. Li, and H. Kang, "PKM2 regulates angiogenesis of VR-EPCs through modulating glycolysis, mitochondrial fission, and fusion," Journal of Cellular Physiology, vol. 235, no. 9, pp. 6204-6217, 2020.

[19] H. Wu, X. Wang, T. Wu, and S. Yang, "miR-489 suppresses multiple myeloma cells growth through inhibition of LDHAmediated aerobic glycolysis," Genes Genomics, vol. 42, no. 3, pp. 291-297, 2020.

[20] K. Wang, X. Jin, Y. Chen et al., "Polyphenol-rich propolis extracts strengthen intestinal barrier function by activating AMPK and ERK signaling," Nutrients, vol. 8, no. 5, article 272, 2016.

[21] M. F. Tolba, S. S. Azab, A. E. Khalifa, S. Z. Abdel-Rahman, and A. B. Abdel-Naim, "Caffeic acid phenethyl ester, a promising component of propolis with a plethora of biological activities: a review on its anti-inflammatory, neuroprotective, hepatoprotective, and cardioprotective effects," IUBMB Life, vol. 65, no. 8, pp. 699-709, 2013.

[22] Y. Zhu, Q. Rao, X. Zhang, and X. Zhou, "Galangin induced antitumor effects in human kidney tumor cells mediated via mitochondrial mediated apoptosis, inhibition of cell migration and invasion and targeting PI3K/AKT/mTOR signalling pathway," Journal of BUON, vol. 23, no. 3, pp. 795-799, 2018.

[23] J. Gao, S. Lin, Y. Gao et al., "Pinocembrin inhibits the proliferation and migration and promotes the apoptosis of ovarian cancer cells through down-regulating the mRNA levels of Ncadherin and GABAB receptor," Biomedicine \& Pharmacotherapy, vol. 120, article 109505, 2019.

[24] H. H. Lee, J. Jung, A. Moon, H. Kang, and H. Cho, “Antitumor and anti-invasive effect of apigenin on human breast carcinoma through suppression of IL-6 expression," International journal of molecular sciences, vol. 20, no. 13, article 3143, 2019.

[25] E. R. Moghadam, H. L. Ang, S. E. Asnaf et al., "Broad-spectrum preclinical antitumor activity of chrysin: current trends and future perspectives," Biomolecules, vol. 10, no. 10, article 1374, 2020.

[26] P. Gao, L. L. Wang, J. Liu et al., "Dihydroartemisinin inhibits endothelial cell tube formation by suppression of the STAT3 signaling pathway," Life sciences, vol. 242, article 117221, 2020.

[27] S. Ganapathy-Kanniappan and J. F. H. Geschwind, “Tumor glycolysis as a target for cancer therapy: progress and prospects," Molecular Cancer, vol. 12, article 152, 2013.
[28] S. Cassim, M. Vucetic, M. Zdralevic, and J. Pouyssegur, "Warburg and beyond: the power of mitochondrial metabolism to collaborate or replace fermentative glycolysis in cancer," Cancers, vol. 12, no. 5, article 1119, 2020.

[29] M. Haidar, A. Lombes, F. Bouillaud, E. J. Kennedy, and G. Langsley, "HK2 recruitment to Phospho-BAD prevents its degradation, promoting Warburg glycolysis by theileriatransformed leukocytes," ACS infectious diseases, vol. 3, no. 3, pp. 216-224, 2017.

[30] M. Hong, X. B. Zhang, F. Xiang, X. Fei, X. L. Ouyang, and X. C. Peng, "MiR-34a suppresses osteoblast differentiation through glycolysis inhibition by targeting lactate dehydrogenase-A (LDHA)," In Vitro Cellular \& Developmental Biology Animal, vol. 56, no. 6, pp. 480-487, 2020.

[31] E. A. Pudova, A. V. Snezhkina, M. V. Ermoschenkova et al., "HK1 and HK2 gene expression in triple negative and luminal a breast cancer," Biologicheskie Membrany, vol. 35, no. 5, pp. 403-406, 2018.

[32] T. Zhang, X. Zhu, H. Wu et al., "Targeting the ROS/PI3K/AKT/HIF- $1 \alpha / \mathrm{HK} 2$ axis of breast cancer cells: combined administration of polydatin and 2-deoxy-d-glucose," Journal of Cellular and Molecular Medicine, vol. 23, no. 5, pp. 37113723, 2019.

[33] X. Shi, L. You, and R. Y. Luo, "Glycolytic reprogramming in cancer cells: PKM2 dimer predominance induced by pulsatile PFK-1 activity," Physical biology, vol. 16, no. 6, article 066007, 2019.

[34] R. Tahtouh, L. Wardi, R. Sarkis et al., "Glucose restriction reverses the Warburg effect and modulates PKM2 and mTOR expression in breast cancer cell lines," Cellular and Molecular Biology (Noisy-le-Grand, France), vol. 65, no. 7, pp. 26-33, 2019.

[35] B. Shashni, K. R. Sakharkar, Y. Nagasaki, and M. K. Sakharkar, "Glycolytic enzymes PGK1 and PKM2 as novel transcriptional targets of PPARgamma in breast cancer pathophysiology," Journal of Drug Targeting, vol. 21, no. 2, pp. 161-174, 2012.

[36] K. Zhu, Y. Li, C. Deng et al., "Significant association of PKM2 and NQO1 proteins with poor prognosis in breast cancer," Pathology-Research and Practice, vol. 216, no. 11, article 153173, 2020.

[37] W. Niu, Y. Luo, X. Wang et al., "BRD7 inhibits the Warburg effect and tumor progression through inactivation of HIF1alpha/LDHA axis in breast cancer," Cell Death \& Disease, vol. 9, no. 5, article 519, 2018.

[38] X. Huang, X. Li, X. Xie et al., "High expressions of LDHA and AMPK as prognostic biomarkers for breast cancer," Breast, vol. 30, pp. 39-46, 2016.

[39] M. Fujita, K. Imadome, V. Somasundaram, M. Kawanishi, K. Karasawa, and D. A. Wink, "Metabolic characterization of aggressive breast cancer cells exhibiting invasive phenotype: impact of non-cytotoxic doses of 2-DG on diminishing invasiveness," BMC Cancer, vol. 20, no. 1, article 929, 2020.

[40] S. Rodic and M. D. Vincent, "Reactive oxygen species (ROS) are a key determinant of cancer's metabolic phenotype," International Journal of Cancer, vol. 142, no. 3, pp. 440-448, 2018.

[41] J. Cao, X. Liu, Y. Yang et al., "Decylubiquinone suppresses breast cancer growth and metastasis by inhibiting angiogenesis via the ROS/p53/BAI1 signaling pathway," Angiogenesis, vol. 23, no. 3, pp. 325-338, 2020.

[42] M. Z. Saleem, M. Alshwmi, H. Zhang et al., "Inhibition of JNKmediated autophagy promotes proscillaridin A-induced 
apoptosis via ROS generation, intracellular $\mathrm{Ca}(+2)$ oscillation and inhibiting STAT3 signaling in breast cancer cells," Frontiers in Pharmacology, vol. 11, article 01055, 2020.

[43] S. Ganapathy-Kanniappan, "Taming tumor glycolysis and potential implications for immunotherapy," Frontiers in oncology, vol. 7, article 36, 2017.

[44] M. S. J. Mangan, E. J. Olhava, W. R. Roush, H. M. Seidel, G. D. Glick, and E. Latz, "Targeting the NLRP3 inflammasome in inflammatory diseases," Nature Reviews Drug Discovery, vol. 17, no. 8, pp. 588-606, 2018.

[45] F. Ghiringhelli, L. Apetoh, A. Tesniere et al., "Activation of the NLRP3 inflammasome in dendritic cells induces IL- $1 \beta-$ dependent adaptive immunity against tumors," Nature Medicine, vol. 15, no. 10, pp. 1170-1178, 2009. 